\title{
Surface deformation evolution in the Pearl River Delta between 2006 and 2011 derived from the ALOS1/PALSAR images
}

\author{
Genger Li ${ }^{1}$, Guangcai Feng ${ }^{2 *}$, Zhiqiang Xiong ${ }^{2}$, Qi Liu², Rongan Xie ${ }^{1}$, Xiaoling Zhu' ${ }^{1}$, Shuran Luo ${ }^{2}$ and Yanan Du ${ }^{3}$
}

\begin{abstract}
This study monitors the land subsidence of the whole Pearl River Delta (PRD) (area: $\sim 40,000 \mathrm{~km}^{2}$ ) in China using the ALOS1/PALSAR data (2006-2011) through the SBAS-InSAR method. We also analyze the relationship between the subsidence and the coastline change, river distribution, geological structure as well as the local terrain. The results show that (1) the land subsidence with the average velocity of $50 \mathrm{~mm} /$ year occurred in the low elevation area in the front part of the delta and the coastal area, and the area of the regions subsiding faster than $30 \mathrm{~mm} /$ year between 2006 and 2011 is larger than $122 \mathrm{~km}^{2}$; (2) the subsidence order and area estimated in this study are both much larger than that measured in previous studies; (3) the areas along rivers suffered from surface subsidence, due to the thick soft soil layer and frequent human interference; (4) the geological evolution is the intrinsic factor of the surface subsidence in the PRD, but human interference (reclamation, ground water extraction and urban construction) extends the subsiding area and increases the subsiding rate.
\end{abstract}

Keywords: Pearl river delta, Natural evolution, Surface subsidence, SBAS-InSAR

\section{Introduction}

Deltas have abundant natural resources, superior natural environment and geographical locations, so they accommodate the most intensive human activities. However, most deltas suffer from geological disasters caused by land subsidence, which damage buildings, railways, highways, subways and underground facilities (water supply pipes, gas and electrical installations), hindering the sustainable development in economy and environment (Ericson et al. 2006; Törnqvist et al. 2008; Wang et al. 2017). About 24 of the 33 major deltas in the world have surface subsidence, including the Pearl River Delta (PRD) in China (Syvitski et al. 2009). As one of the most economically developed and urbanized areas in China, the Pearl River Delta (PRD) has the largest urban agglomeration in the world and the population of 55 million. It has

\footnotetext{
*Correspondence: fredgps@qq.com

${ }^{2}$ School of Geosciences and Info-Physics, Central South University,

Changsha 410083, China

Full list of author information is available at the end of the article
}

suffered many surface deformation disasters, including land subsidence, landslides and collapses (Syvitski et al. 2009; Chen et al. 2012; Ma et al. 2019).

The interferometric synthetic aperture radar (InSAR) technique has been widely used for monitoring surface subsidence in delta areas, including the PRD, because of its wide spatial and long temporal coverage (Higgins et al. 2014). Using C-band ENVISAT/ASAR data, Chen et al. (2012) mapped the surface deformation in the range of -15 to $15 \mathrm{~mm} /$ year from 2006 to 2010 . Based on the $\mathrm{X}$-band and COSMO-SkyMed data of Guangzhou and Foshan, Alex et al. (2018) reported that the surface deformation was in the range of -35 to $10 \mathrm{~mm}$ /year between 2011 and 2017. Ma et al. (2019) investigated the subsidence of the Guangdong-Hong Kong-Macao Greater Bay Area and found that the overall subsidence ranged from 0 to $112.3 \mathrm{~mm} /$ year, according to the 2015-2017 Sentinel-1 images. The results of these studies show similar subsidence patterns, but significantly different maximum subsidence orders (15 to $112.3 \mathrm{~mm} /$ year). Using a new kind of SAR dataset with long wavelength may address 
this controversy. The L-band ALOS1/PALSAR data have much longer wavelength than the C-band ENVISAT ASAR and X-band COSMO-SkyMed data, so they can detect much more reliable deformation information in densely vegetated regions, like PRD. Therefore, we use ALOS1/PALSAR data to assess the order of the subsidence in PRD during 2006-2011.

The surface deformation evolution in delta areas is contributed by both natural factors and anthropogenic interference. For the PRD area, many related studies focused on the local surface deformation caused by human activities, including ground water extraction and engineering construction (Wang et al. 2012, 2017; Chen et al. 2012; $\mathrm{Xu}$ et al. 2016; Alex et al. 2018). These studies provided a lot of useful information for understanding the local subsidence pattern, but they paid little attention on the natural evolution factors, such as river distribution, coastline change and the local terrain.

In this study, we use the small baseline subset InSAR (SBAS-InSAR) method to map the surface deformation over the entire PRD (area: $\sim 40,000 \mathrm{~km}^{2}$ ) using 162 ALOS1/PALSAR images from 3 paths and 8 frames acquired between 2006 and 2011. The deformation results are verified by cross-validation of nearby path velocity rate and field investigation data. Then we analyze the temporal-spatial distribution characteristics of the deformation in the PRD, based on which we investigate the relationship between the subsidence and natural evolution factors as well as human interferences.

\section{The geological background and evolution of the PRD \\ Geological background}

The PRD is located in the south-central part of Guangdong Province, bordering the South China Sea (Fig. 1). It is a plain formed by the alluvium from the Xijiang River, Beijiang River and Dongjiang River (Huang and Zhang 2004). It covers an area of about $42,200 \mathrm{~km}^{2}$ from $112.5^{\circ}$ to $114.25^{\circ} \mathrm{E}$ and $21.83^{\circ}$ to $23.6^{\circ} \mathrm{N}$. This delta is high in the north and low in the south, with small undulations. Influenced by the subtropical monsoon climate, the PRD has abundant rainfall and is often struck by typhoons and rainstorms. More than 300 river sections, with a total length of about $1740 \mathrm{~km}$ and an area of over $9750 \mathrm{~km}^{2}$, form a dense and complex network (Huang and Zhang 2004).

Bedrock ( $\beta$ ), hidden karst $(C)$, Quaternary loose soil (Q4) and soft soil form the geological structure of this area (Fig. 2). The bedrock is mainly composed of granite and partially of metamorphic sandstone, clastic rocks and basalt. The hidden karst, composed of limestone and shale, concentrates in the Guanghua Basin. The Quaternary loose soil and soft soil form alluvial layers, which are thick in the front part (such as Zhongshan city

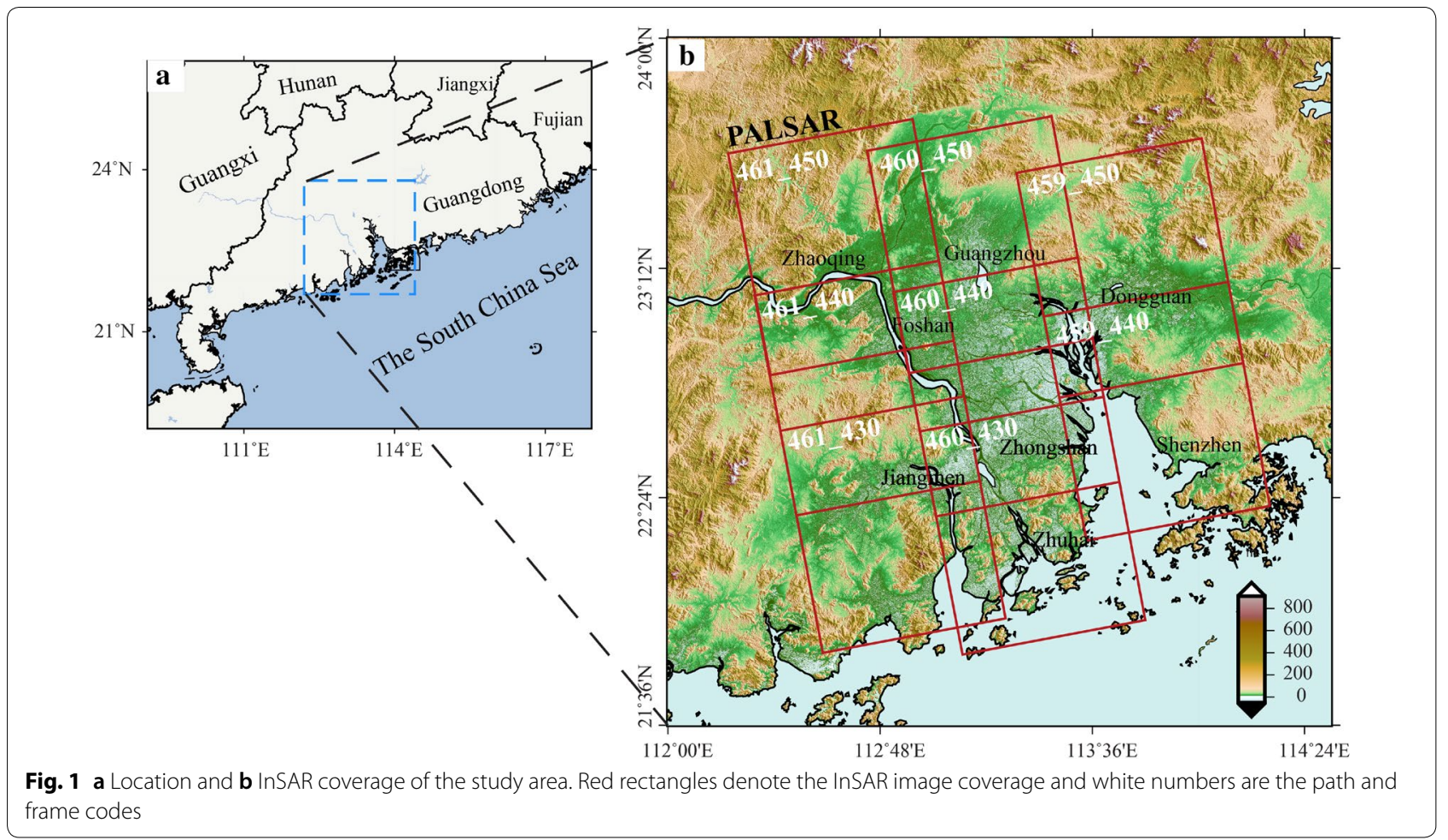


and Nansha district of Guangzhou city) and thin in the rear part of the delta. These alluvial layers were formed between the Pleistocene and the Holocene (Zong et al. 2009), with the thickness of most parts varying from 5 to $36 \mathrm{~m}$, and the maximum as $55 \mathrm{~m}$. These soft layers mostly distribute along the river and in the flat terrain of the delta (Li et al. 1991).

\section{River and coastline evolution of the PRD}

The rich rainfall and abundant river flow carry sediments from the upper reaches to the lower reaches. The PRD is flat, so $20-50 \%$ of the total sediment transported deposits in the river channel (Hu et al. 2011). Since the Tang dynasty, the population of the PRD started soaring. The agricultural development brought by the population growth accelerated the change of land use and led to serious soil and water loss. The increased sediment discharge contributed to the growth of the estuarine delta and outward extending of the coastline (McManus 2002; Maselli and Trincardi 2013). In the past 6000 years, the coastline of the PRD has been pushed outward $100 \mathrm{~km}$ (see Fig. 2) (Fyfe et al. 1999; Zong et al. 2009).

Human activities also play an important role in the morphology and geomorphology evolution of the PRD, especially in the last 100 years. The influence of human

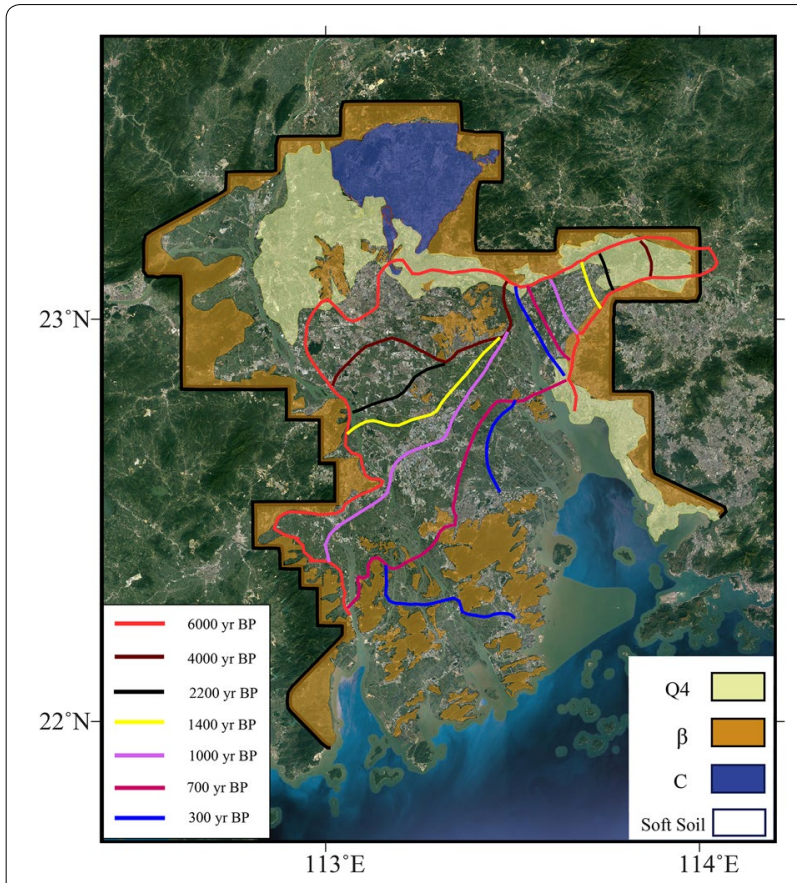

Fig. 2 Geological formation map of the Pearl River Delta (PRD). The colors inside the region outlined by the black line denote the Quaternary loose soil (Q4), bedrock ( $\beta$ ), hidden karst (C), and soft soil. Curves of different colors represent coastlines of different time periods (Modified from Li et al. 1991) activities even exceeded that of natural factors (Ericson et al. 2006; Syvitski and Satio 2007). And some researchers, based on the remote sensing images and historical maritime map, found that the reclamation is the main factor of the PRD morphology and geomorphology changes over the past 100 years (Seto and Kaufmann 2006; Li and Damen 2010; Wang et al. 2013).

\section{Methodology and results}

\section{SBAS-InSAR data processing}

Given a differential InSAR pair acquired at moments $t_{\mathrm{A}}$ and $t_{\mathrm{B}}$, the unwrapped phase is

$$
\begin{aligned}
\delta \phi_{\mathrm{obs}}= & \phi\left(t_{\mathrm{B}}\right)-\phi\left(t_{\mathrm{A}}\right) \approx \frac{4 \pi}{\lambda} \Delta d+\frac{4 \pi}{\lambda} \frac{B_{\perp j} \Delta z}{r \sin \theta} \\
& +\Delta \phi_{\mathrm{atm}}+\Delta_{n_{j}},
\end{aligned}
$$

where $\delta \phi_{\text {obs }}$ is the phase of one pixel in differential interferogram, $\Delta d$ is the line of sight (LOS) deformation of a pixel between two images, $\Delta z$ is the topographic error, $\Delta \phi_{\text {atm }}$ is the atmospheric delay phase, and $\Delta_{n_{j}}$ is the phase noise. Equation (1) can be written in a matrix form as follows:

$$
\left[\begin{array}{ccc}
\frac{4 \pi}{\lambda} \Delta t_{1} & \frac{4 \pi}{\lambda} \frac{B_{\perp 1}}{r \sin \theta} \\
\frac{4 \pi}{\lambda} \Delta t_{2} & \frac{4 \pi}{\lambda} \frac{B \perp 2}{r \sin \theta} \\
\vdots & \vdots
\end{array}\right]\left[\begin{array}{c}
v \\
\Delta z
\end{array}\right]=\left[\begin{array}{c}
\delta \phi_{1} \\
\delta \phi_{2} \\
\vdots
\end{array}\right],
$$

where $v$ is the deformation rate. Following the SBASInSAR procedures (Berardino et al. 2002), we solve Eq. (2) by the least squares method, and obtain the linear deformation rate and the topographic error of each pixel. Subtracting topographic error and linear deformation phase from each differential interferogram, we get the residual phase. The residual phase consists of nonlinear deformation, atmospheric delay and noise. Taking the residual phase as the observation value, we obtain the time series phase of each SAR image by the singular value decomposition (SVD) method. We use the temporal high pass and spatial low pass filtering to obtain the atmospheric phase of each SAR image. Then, atmospheric errors are subtracted from each interferogram. Finally, the SVD method is used to calculate time series of each pixel. Figure 3 shows the flowchart of the SBAS-InSAR method.

In this study, the L-band ALOS1/PALSAR data from 3 tracks are used to obtain the subsidence that occurred in the PRD between 2006 and 2011 (see Fig. 1 and Appendix $1)$. The data are processed with the GAMMA software (Werner et al. 2003). The multi-look operation of $6 \times 16$ pixels in the range and azimuth directions is adopted to reduce phase noise and calculation burden before phase unwrapping. The result's resolution after multi-looking 


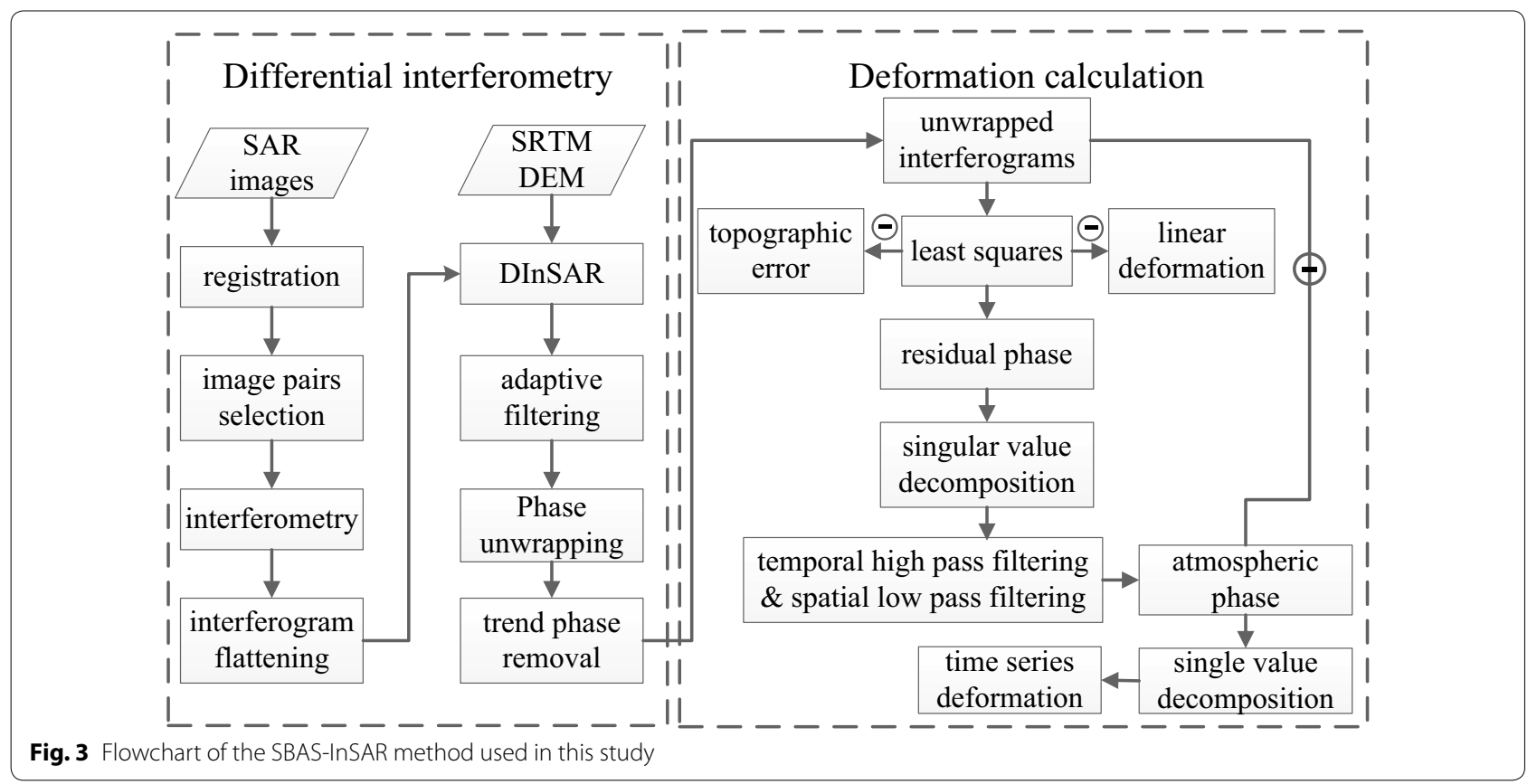

is about $50 \mathrm{~m} \times 50 \mathrm{~m}$. The interferometric pairs with the temporal baseline $<700$ days and perpendicular baseline $<1000 \mathrm{~m}$ are selected to reduce the decorrelation. The topographic phase is removed using the 1 -arcsecond ( $30 \mathrm{~m}$ ) Shuttle Radar Topography Mission DEM (Jarvis et al. 2008). A modified Goldstein filter is used to reduce noise phases (Li et al. 2008) and a mask with a coherence less than 0.4 is adopted to weaken the effect of low coherence regions (sea, isolated islands, etc.). Finally, the phase unwrapping is performed by the minimum cost flow algorithm (Costantini 1998). The polynomial fitting is used to remove the long wavelength orbital errors in the unwrapped phase.

\section{Surface subsidence results}

Using the method described in "SBAS-InSAR data processing" section, we obtain the deformation rate map of the PRD between 2006 and 2011 (Fig. 4). Figure 4a presents the average deformation rate derived from the ALOS1/PALSAR image. The hinterland is stable and the subsidence is mainly distributed in the front part of the delta and the coastal area. The average subsidence rate ranges from 10 to $50 \mathrm{~mm}$ /year, with the maximum deformation rate of $>70 \mathrm{~mm} /$ year. Some regions have sporadic subsidence with a rate between 10 and $30 \mathrm{~mm}$ /year, such as the northeast part of Guangzhou city and the southeastern part of Zhaoqing city (outlined by the red dotted line in Fig. 4).

Two large subsidence cones (S-1 and S-2 in Fig. 4b) are observed in the front part of the delta. The most serious land subsidence is observed in the junction area of Zhongshan city and Jiangmen city (such as Jianghai district of Jiangmen city and Henglan town of Zhongshan city), with an area of $160 \mathrm{~km}^{2}$. In this region, the subsidence rate of the center ranges from 30 to $50 \mathrm{~mm} /$ year, even $>70 \mathrm{~mm} /$ year in some parts, and the average cumulative deformation is about $35 \mathrm{~cm}$ from 2006 to 2011 (Fig. 4d). Subsidence cone S-2 covers Jinwan district of Zhuhai city and Tanzhou town of Zhongshan city, with an area of $230 \mathrm{~km}^{2}$. Besides the two large subsidence cones, there are some areas with smaller subsidence rates, such as Doumen district of Zhuhai city and Xinhui district of Jiangmen city.

No large subsidence cone is found in the coastal areas. The subsidence areas scatter on the two sides of the Lingding Bay (see Fig. 4c), such as Nansha district of Guangzhou city and Nanlang town of Zhongshan city and Tangjia town of Zhuhai city. The subsidence rate is between 20 and $40 \mathrm{~mm} /$ year, and is over $50 \mathrm{~mm} /$ year in some regions. The subsidence rates in the coastal areas of Dongguan and Shenzhen are smaller. For example, the subsidence rates of Chang'an town in Dongguan and Bao'an district in Shenzhen are 10 and $25 \mathrm{~mm} /$ year, respectively.

\section{Results verification}

In the verification, we compared the observations of Area1 and Area2 during the same period, which are the overlapping areas of Path 461 and Path 460 (Fig. 4a). Area1 is stable but Area2 has obvious subsidence, so 


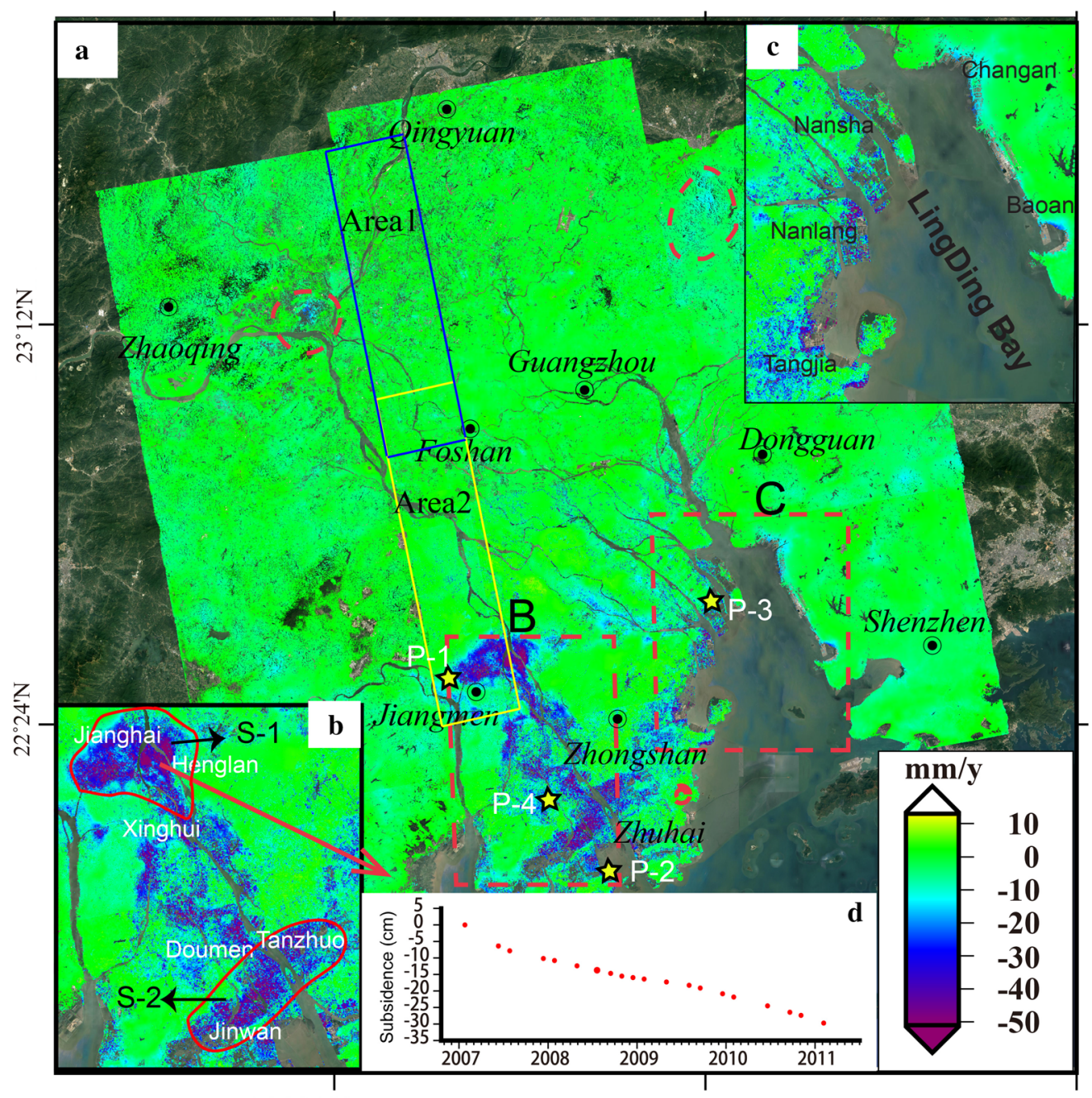

$112^{\circ} 48^{\prime} \mathrm{E}$

$113^{\circ} 36^{\prime} \mathrm{E}$

$114^{\circ} 24^{\prime} \mathrm{E}$
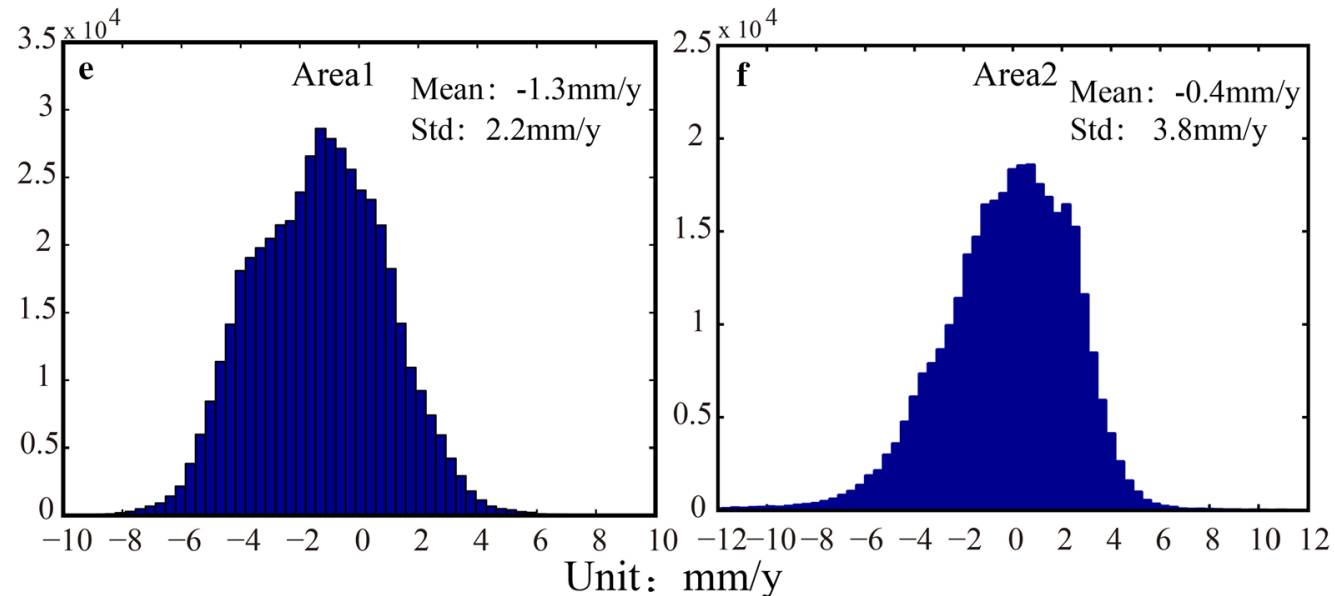

Fig. 4 Surface deformation in the PRD estimated by SBAS-InSAR. a The deformation rate map from 2007 to 2011 . The red dotted line outlines the subsidence area. The blue and yellow rectangles are the overlapping areas of paths 460 and 461 in frame 440 (Area1) and 450 (Area2), respectively. The field observation was carried out in the place marked by yellow stars. b, c zoom-ins of areas B and C, respectively. S-1 and S-2 in $\mathbf{b}$ are two large subsidence cones. $\mathbf{d}$ The time series of the subsidence cone S-1. e, $\mathbf{f}$ the histograms of the difference of the average deformation rate of Area 1 and Area 2 derived from different frames, respectively 
they can verify the results of different subsidence levels. As Fig. 4e, f show, the velocity difference in Area1 is between -8 and $5 \mathrm{~mm} /$ year, and the overall mean value is $-1.3 \mathrm{~mm} /$ year with a variance of $2.2 \mathrm{~mm} /$ year. In Area2, the velocity difference is between -10 and $6 \mathrm{~mm} /$ year, the mean value is $-0.4 \mathrm{~mm} /$ year, and the variance is $3.8 \mathrm{~mm} /$ year. Because of decorrelation, atmospheric delays and different incidence angles, the results of the overlapping areas of adjacent paths, like Area1 and Area2, are slightly different, so the uncertainty $(2.2 \mathrm{~mm} /$ year and $3.8 \mathrm{~mm}$ /year) between different paths is reasonable. To further verify the results, we did field investigations in some cities of the PRD, including Jiangmen city, Zhuhai city and Guangzhou city (see Fig. 5). The field observation confirmed the model results. We also reprocessed the data using the IPTA method (Werner et al. 2003). The details of data processing and result comparison are shown in Appendix 2. The result comparison also confirms that the order and patterns of surface deformation are reliable.

\section{Discussion}

Surface deformation in the PRD is usually caused by the joint force of natural geological evolution and human activities. Natural factors include sediment consolidation, tectonic activity, sea level rise and tidal load ( $\mathrm{Hu}$ et al. 2018). Human activities are land reclamation, groundwater extraction, engineering construction and so on (Wu et al. 2016; Wang et al. 2017). Based on the subsidence results, we analyze the relationship between the subsidence and natural factors and human interference.

\section{Surface subsidence of the PRD area between 2006 and 2011}

As shown in Table 1 , the average subsidence rate ranges from 10 to $50 \mathrm{~mm} /$ year, with the maximum rate $>70 \mathrm{~mm} /$ year, and the regions with the subsidence rate $>30 \mathrm{~mm} /$ year are as large as $122 \mathrm{~km}^{2}$.

Both the order and the area of surface subsidence we obtained are much larger than that of Chen et al. (2012) who used the ENVISAT ASAR datasets (20062010) to map the surface subsidence of the PRD. In the PRD, the areas suffered rapid subsidence have

\section{Table 1 Area of the regions with different subsidence velocities}

\begin{tabular}{llllll}
\hline Subsidence velocity (mm/year) & $10-20$ & $20-30$ & $30-40$ & $40-50$ & $>50$ \\
Area (unit: $\mathrm{km}^{2}$ ) & 781 & 210 & 91 & 26 & 5 \\
\hline
\end{tabular}
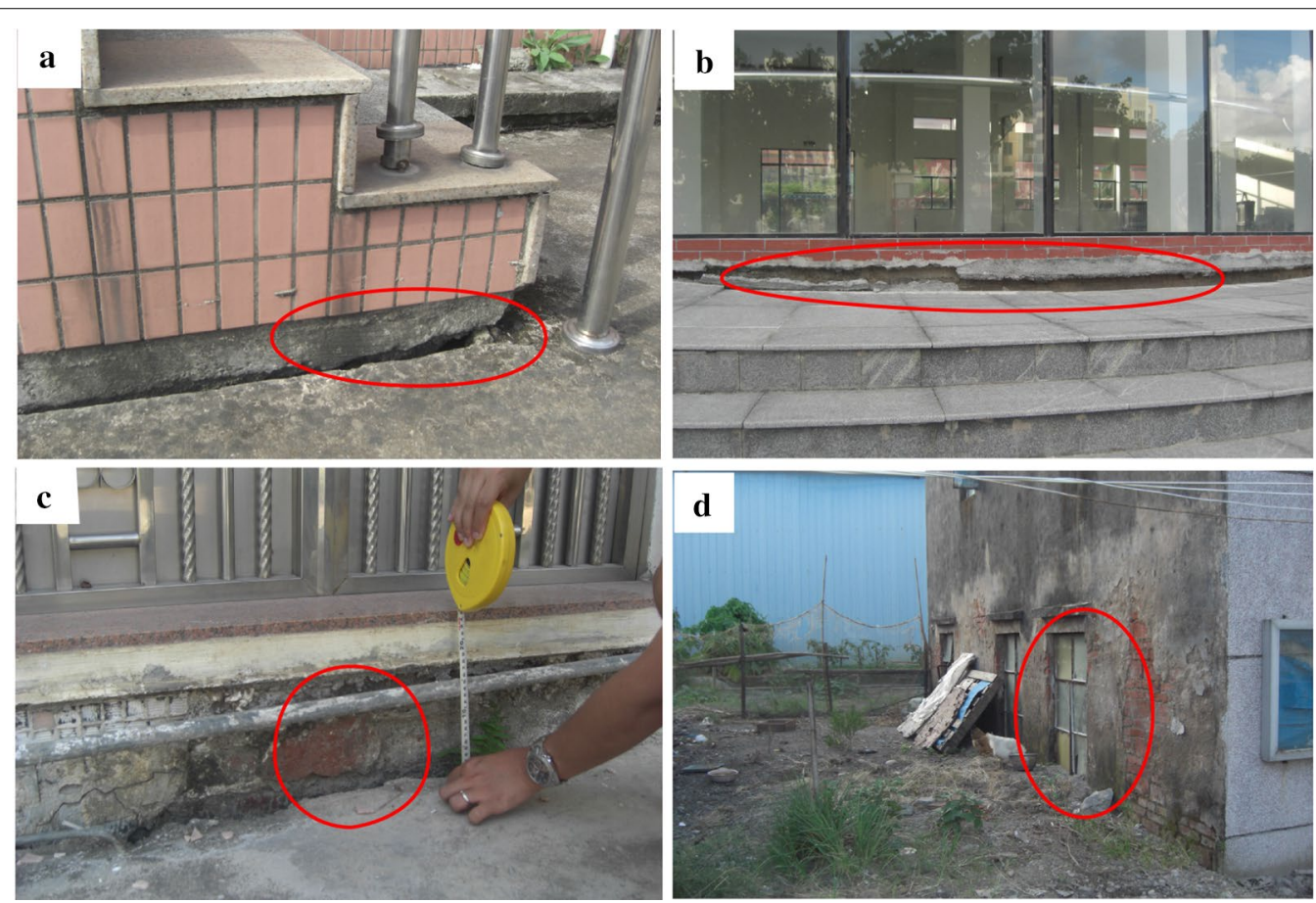

Fig. 5 Photos of the field investigation in the areas denoted by the yellow stars in Fig. 4. a Xinhui port in Xinhui district, Jiangmen city (P-1 in Fig. 4a). The ground subsided about $5 \mathrm{~cm}$ relative to the steps; $\mathbf{b}$ the Kangdelai Medical city in Jinwan district, Zhuhai city (P-2 in Fig. 4a). The steps have separated from the building; c a building in Honghai village, Wanhaisha town, Nansha district, Guangzhou (P-3 in Fig. 4a). The underground pipeline has exposed because of the ground subsidence; $\mathbf{d}$ a house in Sanban village, Hongqi town, Jinwan district, Zhuhai city (P-4 in Fig. 4a). The windows have submerged into the ground 
decorrelation due to the reclamation, vegetation coverage and river distribution. ALOS1/PALSAR (L-band) have longer wavelength than ENVISAT ASAR (C-band), so their images have stronger deformation detection ability than the latter, and the detected maximum deformation is larger than that of the latter. Besides wavelength, the revisit cycle of SAR data is also very important for rapid surface deformation monitoring. The revisit cycle of the ENVISAT ASAR data is 35 days, but it is irregular in the PRD area, and sometimes is up to half a year. This may cause the high subsidence rate points in ENVISAT ASAR measurement missing or significantly less than that of ALOS1/ PALSAR data.

Ma et al. (2019) used Sentinel-1A/B (2015-2017) to map the surface subsidence of the PRD, and got similar result with ours, which is much larger than that of Chen et al. (2012). The Sentinel-1A/B has a revisit cycle of 6-12 days, so their images have higher coherence and better rapid deformation detection ability than the ENVISAT ASAR dataset in this study. The consistency between our results and Ma's results indicates that the subsidence in the PRD is stable and experienced continuous and rapid surface subsidence from 2006 to 2017.

\section{Natural factors}

\section{River distribution and coastline evolution}

Superimposing the river distribution map of the PRD on the deformation rate map (see Fig. 6a), we find that most subsidence areas are distributed along rivers, especially those in the front part of the PRD, where the river networks are dense (Chen et al. 2012). The coastline of the PRD continues pushing outward as silt keeps on depositing at the junction of land and sea. The geological structure formed by the highly compressible soil layers, however, is inherently unstable. The PRD is mainly composed of soft soil layers with high water content and compressibility, poor permeability, low bearing capacity and shear strength (Gebremichael et al. 2018), which easily leads to surface deformation. Most of the soft soil layers formed by sediment deposition are distributed along rivers, so subsidence usually occurs along rivers when those areas were developed by human activities and engineering construction.

The coastline formation time also has influences on the stability of the ground structure, as newly formed soil has a shorter consolidation period and may bring larger subsidence. The map of the coastline changes over the past 6000 years (see Fig. 6b) show that almost all the subsidence areas are distributed in the regions formed in the

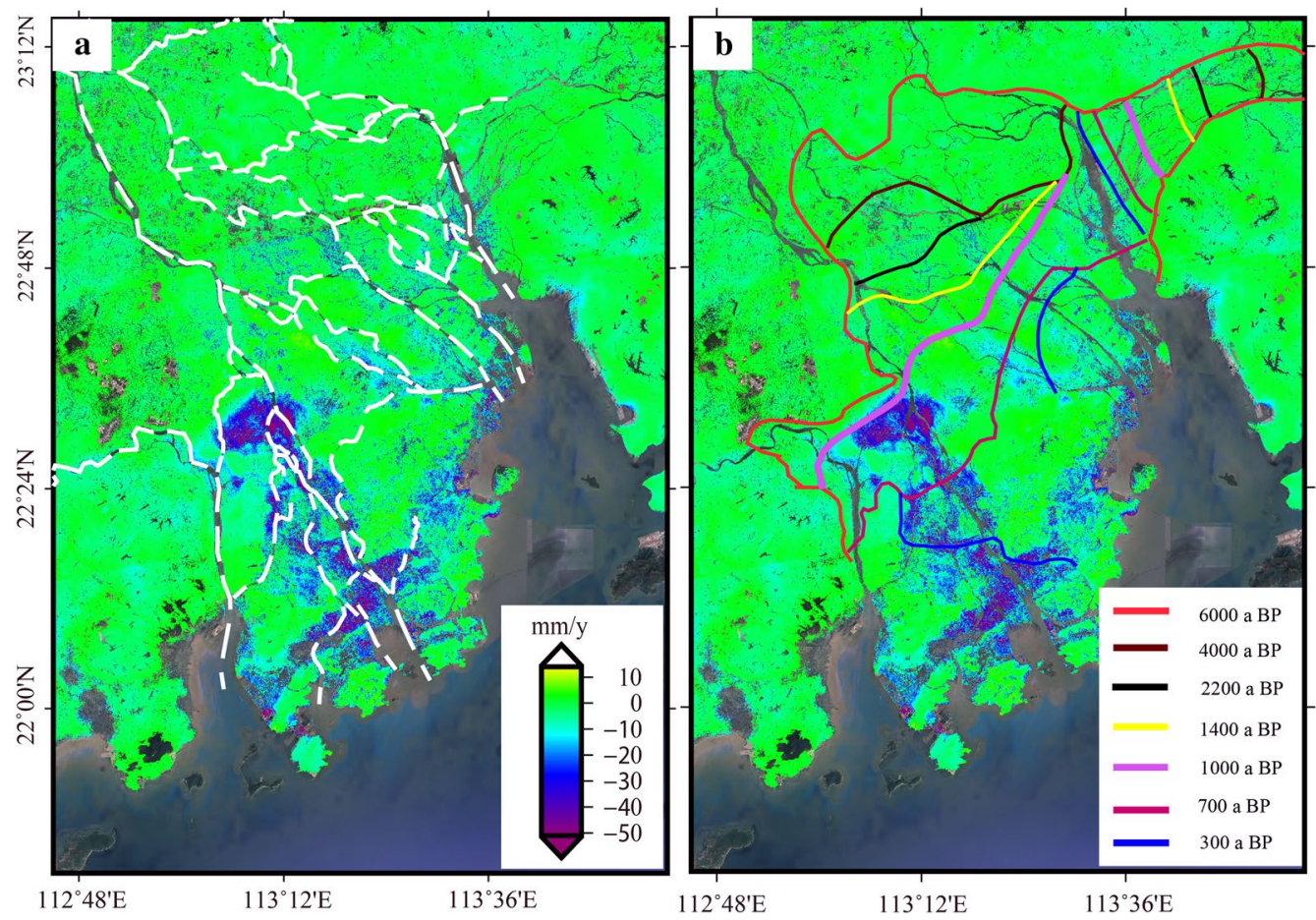

Fig. 6 a Distribution map of the rivers in the PRD. The white dotted lines represent the rivers. $\mathbf{b}$ Coastlines of the PRD in the latest 6000 years. The background is the average displacement velocity map of the PRD (Modified from Li et al. 1991) 
latest 1000 years. The land subsidence of the PRD has a high correlation with the distribution of Quaternary sediments (see Fig. 2). This has been validated in various delta regions of the world. For example, in the Fraser River Delta of Canada, the surface slowly sinks with an annual rate of 1-2 mm/year (Mazzotti et al. 2009), which is mainly caused by the consolidation of shallow Holocene sediments (soft soil). In the Mississippi Delta, the subsidence rate due to soil compaction is relatively large. The settlement speed of the soft soil area formed thousands of years ago is about $5 \mathrm{~mm} /$ year, and that of the area formed in the past tens to hundreds of years exceeds $10 \mathrm{~mm} /$ year (Törnqvist et al. 2008).

\section{Geological structure}

As shown in Fig. 7, the areas located in bedrock distribution areas $(\beta)$ (see Fig. $7 \mathrm{~b}$ ) are very stable, and most surface subsidence occurred in the soft soil area. Before the modern delta was formed ( 6000 years ago), the bedrock areas were isolated islands, and most of them were composed of bare rocks. As the coastline moved outward, those islands gradually merged into the land. So, the geological structures of these regions are stable. As Fig. 7a, b shows, there is a strong positive correlation between the thickness of the soft soil and the deformation rate. Higgins et al. (2014) drew the similar conclusion in the study of the subsidence of Ganges-Brahmaputra Delta. Therefore, the soft soil thickness can be inverted by the correlation between surface deformation and drilling data.

Soft soil is mainly distributed along rivers and in the low-lying areas of the delta, where the erosion caused by sea level rise is serious. In Fig. 8a, the green area is lower than the average sea level, and it accounts for more than $1 / 3$ of the entire onshore delta. The subsidence in the area below the sea level is outlined by the yellow line in Fig. 8b. The comparison between Fig. 8a, b shows that the land subsidence in the front and middle parts of the PRD concentrates in the area below the mean sea level. The annual average tidal range of the Pearl River Estuary is $1.0-1.7 \mathrm{~m}$, and the load generated by tides and storm surges can cause settlements of a few millimeters to centimeters (Ye and Preiffer 1990). The low-lying areas, affected by tides, sea level rise, storms and floods, are also the areas accommodating severe subsidence disasters. According to the Intergovernmental Panel on Climate Change (IPCC), the sea level had risen $0.19 \mathrm{~m}(1.7 \mathrm{~mm} /$ year) between 1901 and 2010. And the rise is accelerating (Zhang and Church 2012). These low-lying areas would suffer from both seawater erosion and surface subsidence in the future.

\section{Human activities \\ Reclamation}

In the 1960s, the large-scale reclamation in the PRD rapidly reshaped the coastline. The reclamation rate between 1970 and 1995 reached $21 \mathrm{~km}^{2} /$ year and then slowed down. We collect the coastline data from 1850 to 2015 with a time span of 165 years, and depict the changes in Fig. 9. The blue line is the PRD coastline in 1850, and the red lines are the coastlines of different periods. In the past 165 years, the coastline and landforms have undergone tremendous changes. A large area of land has been
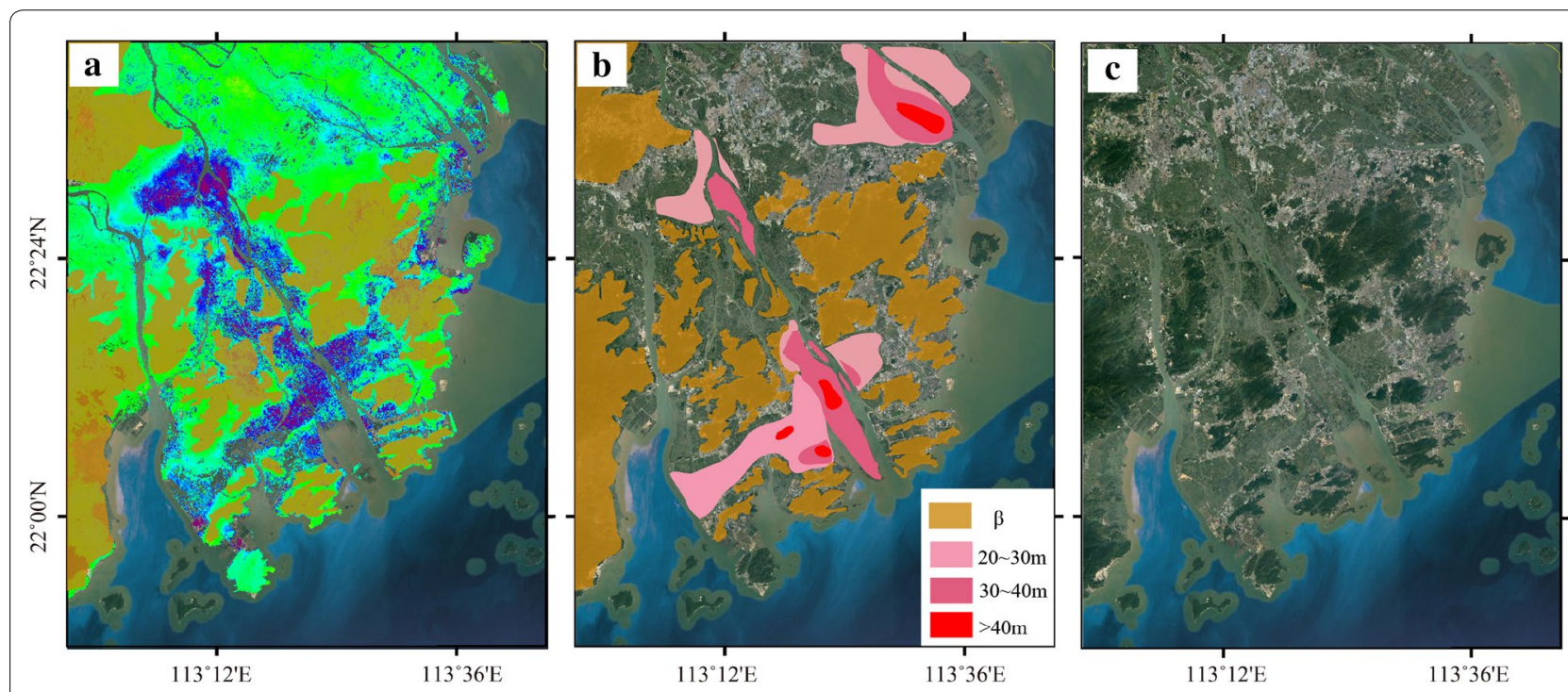

Fig. 7 a The distribution of subsidence and bedrocks in the PRD, b soft soil thickness distribution in the PRD. $\beta$ indicates the bedrock distribution; $\mathbf{c}$ optical imagery of the area of interest 


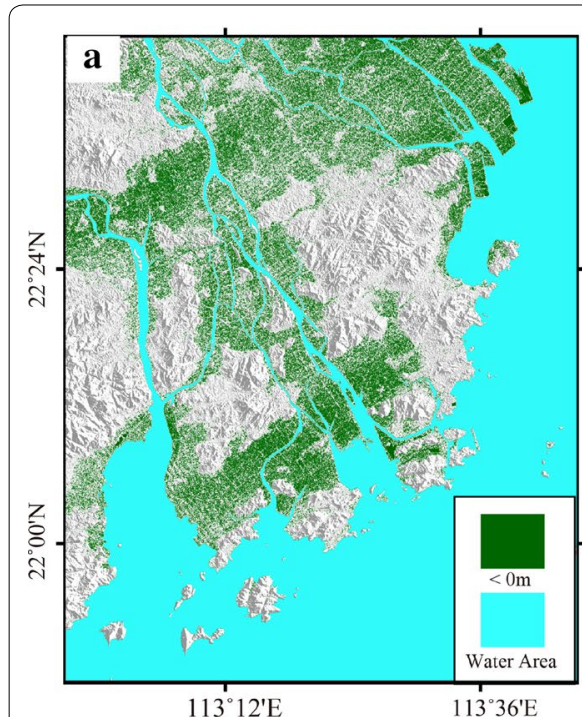

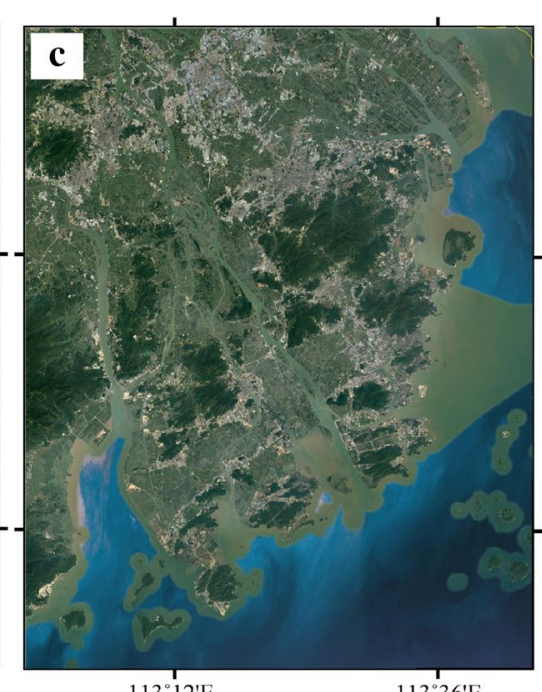

$113^{\circ} 12^{\prime} \mathrm{E}$

$113^{\circ} 36^{\prime} \mathrm{E}$

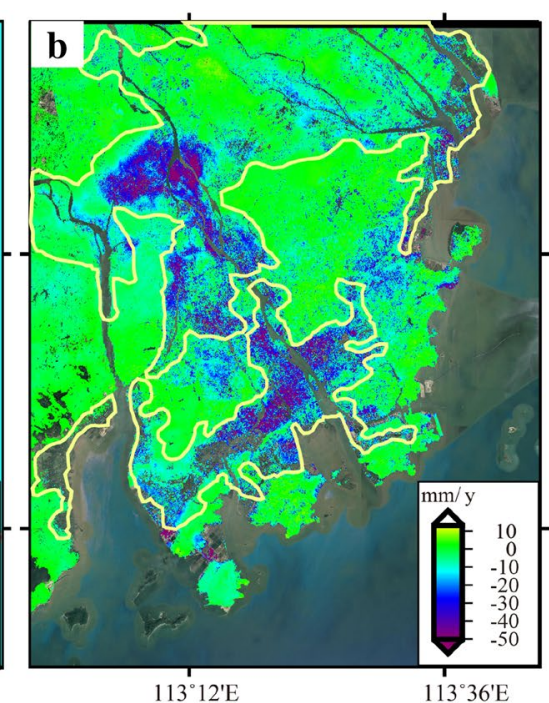

Fig. 8 a DEM of the PRD. Green indicates the area below the average sea level; $\mathbf{b}$ subsidence rate map of the PRD. The area below the mean sea level is outlined by the yellow line. c Optical imagery of the area of interest
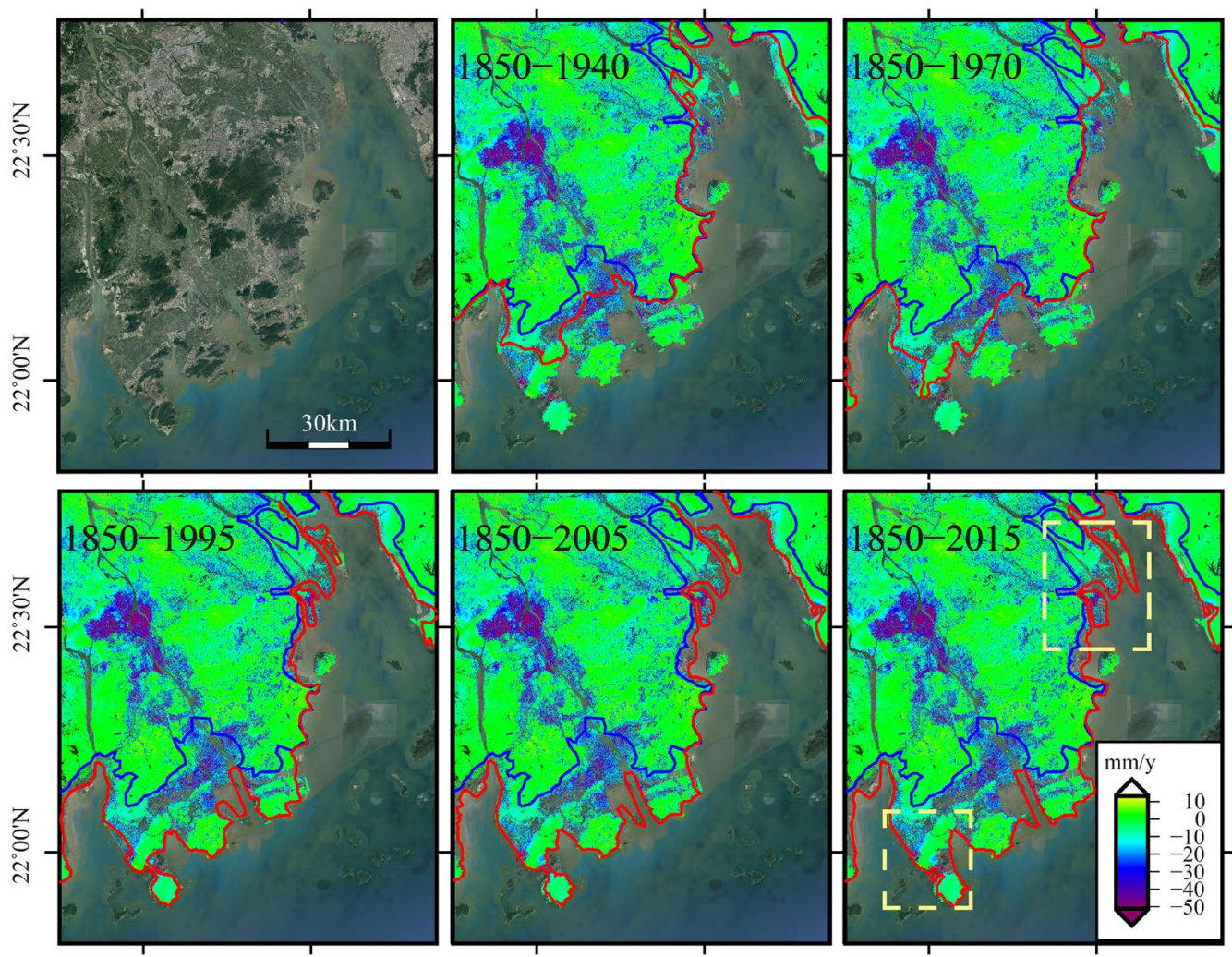

$113^{\circ} 12^{\prime} \mathrm{E}$

$113^{\circ} 36^{\prime} \mathrm{E}$

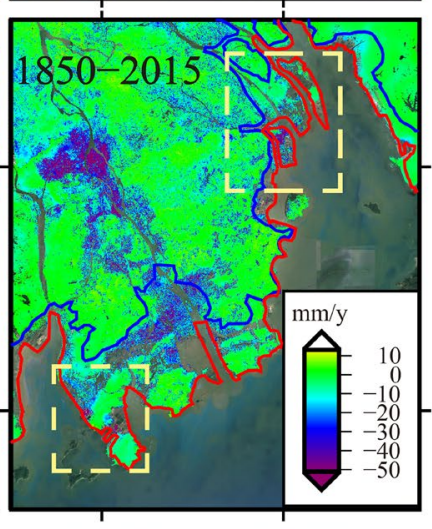

Fig. 9 Optical image and the coastline changes in the PRD. The blue lines represent the coast line of the PRD in 1850, the red lines represent the coast line of the PRD in different time 
reclaimed from waters and tidal flats. As the shoreline gradually moved towards the sea, more than 20 islands gradually merged into the mainland. By 2015 , almost all the tidal flats in 1850 had been reclaimed into land.

As shown in Fig. 9, the reclaimed areas are also the area with the largest subsidence rate (subsidence rate: $>50 \mathrm{~mm} /$ year), including the coastal areas of Zhuhai, Guangzhou, Dongguan and Shenzhen. Most of these areas were reclaimed in the last 30 years (Xu et al. 2016; Huang and Zhang 2004), so the soil layers in these areas are unstable. Furthermore, the landfill materials are sediments, which causes subsidence by self-consolidation.

We select two areas, Nansha district of Guangzhou city and Jinwan district of Zhuhai city (outlined by the yellow dotted line in Fig. 9), to analyze the relationship between the subsidence and reclamation in detail. As shown in Fig. 10, these two areas were reclaimed from the sea a few decades ago. In 1984 (see Fig. 10a), Longxue and Hengmen were small islands, but they gradually expanded outwards and formed the basic shape of the current island in 2016 (see Fig. 10b-e). The area of Longxue island cofferdam grew about 150 times in 35 years. The newly reclaimed regions have serious subsidence, and the maximum subsidence rate is $75 \mathrm{~mm} /$ year (see Fig. 10f). Figure $10 \mathrm{~g}-\mathrm{k}$ shows the variation of the reclaimed region in Jinwan district of Zhuhai city, where two small subsidence cones are obvious (see Fig. 10l). Gaolan island, which was an island before 2004, is connected to the land in 2010 (see Fig. 10j). The connection area accommodates the subsidence cones, where the maximum subsidence is $87 \mathrm{~mm}$ /year (see Fig. 10).

Many countries, such as the Netherlands (Hoeksema 2007), the United Kingdom (Wali 1975), Japan (Suzuki 2003) and Singapore (Douglas and Lawson 2003; Xu et al. 2016), have reclaimed land from the sea for the coastal industries and agricultural development, as well as for storm defense. Surface deformation monitoring in the Nile Delta and the Tiber Delta indicates that the reclaimed area is the most severely subsiding area (Stramondo et al. 2008; Marriner et al. 2012). So the long-term monitoring of the reclaimed area in the PRD is necessary.

\section{Other human interventions}

The PRD region is an economic center of south China, where factories, buildings, farmlands, and fisheries are densely distributed. The deposits consolidation and reclamation are the main factors for the land subsidence in deltas, but they alone cannot cause subsidence as high as $70 \mathrm{~mm} /$ year in small regions. We took the subsidence cone S-1 (see Fig. 4b) as an example to investigate the reason of local rapid subsidence. Through field investigation, we found that fish ponds are widely distributed in the coastal area of Jianghai (Fig. 11a), where large area land subsidence occurred. Aquaculture needs great amount of freshwater. Aggressive extraction of groundwater leads to the rapid drop of the groundwater level and causes subsidence, even settlement cones. Two

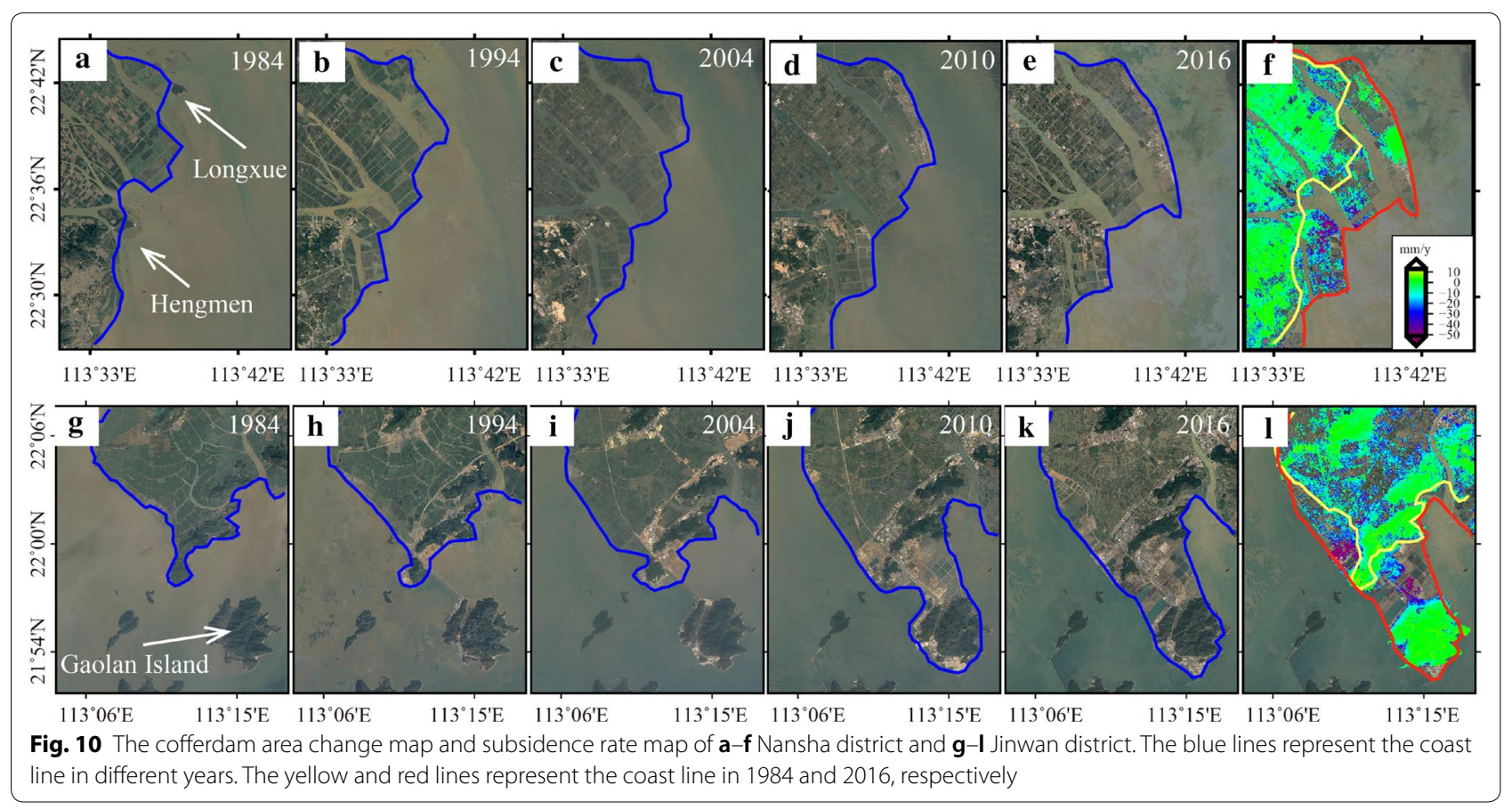



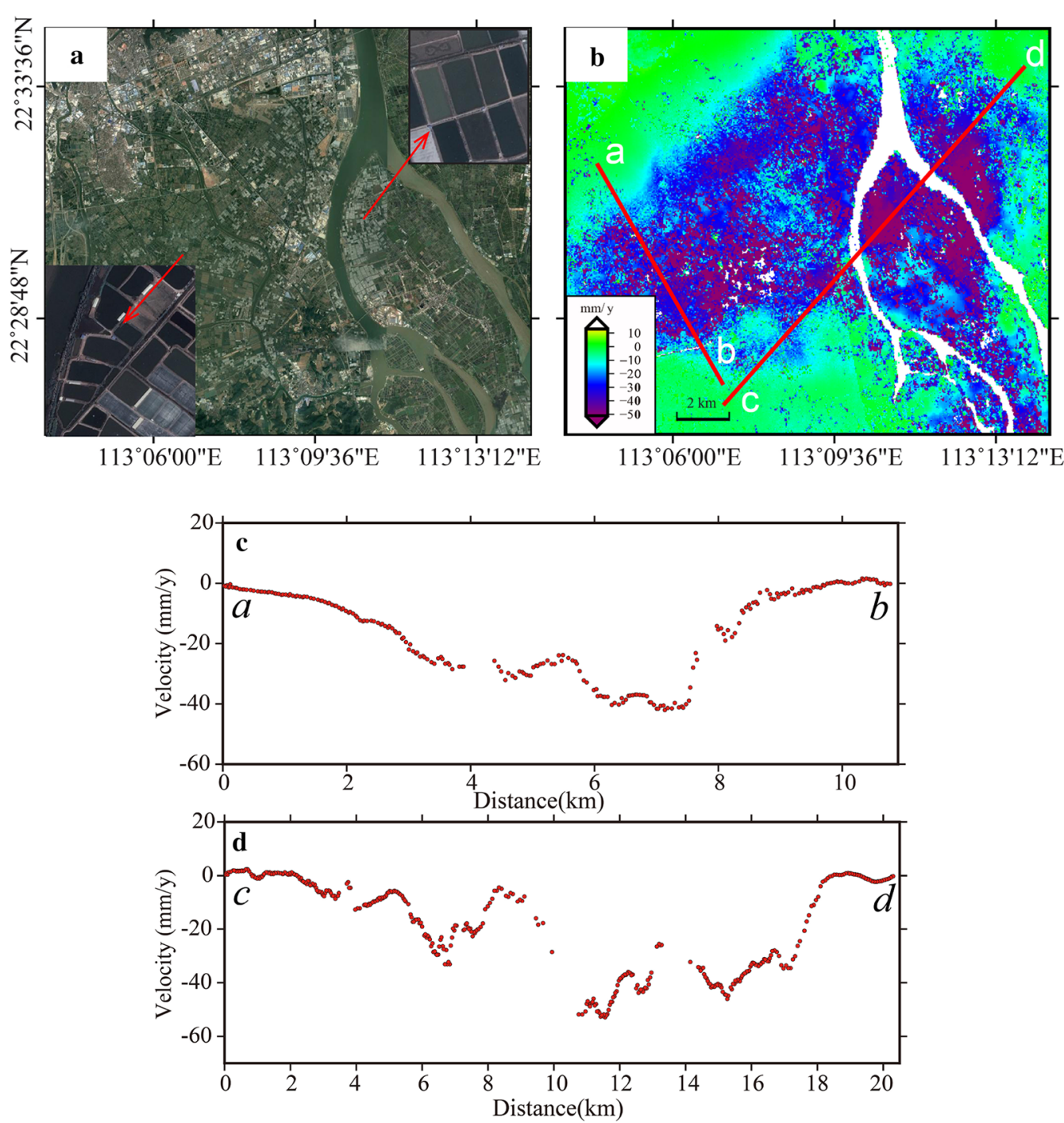

Fig. 11 a Optical image of S-1 (Fig. 4). The insets are the zoom-ins of the base map, where the fish ponds are clearly visible. b Average displacement velocity map of S-1. c, d the average subsidence velocities of profiles ab and cd, respectively

profiles along S-1 (Fig. 11b), ab and cd, are used to show the settlement characteristics (Fig. 11c, d).

The subsidence caused by excessive groundwater extraction is common in delta areas. In the Mekong Delta, the average land subsidence rate has reached $16 \mathrm{~mm} /$ year as more than 250,000 ha of land has been converted from rice fields to shrimp ponds since 2000 (Erban et al. 2014). Oil and groundwater extraction play a key role in the land subsidence in the modern Yellow River Delta, and the land subsidence caused by aquaculture is up to $250 \mathrm{~mm} /$ year (Higgins et al. 2013). Therefore, we conclude that natural factors coupled with human activities cause the subsidence in the PRD. The evolution of the PRD determines the location of the subsidence areas, and human activities have become the direct cause of the settlement. Therefore, we should pay more attention to the subsidence caused by human activities.

\section{Conclusions}

We map the surface deformation of the entire PRD using the ALOS1/PALSAR images from 2006 to 2011. The results show that the areas with serious subsidence concentrate in the front part of the delta and the coastal areas. The two large settlement funnels in the 
front part of the PRD have the average settlement rates of $30-50 \mathrm{~mm} /$ year, and the maximum settlement rate of larger than $70 \mathrm{~mm} /$ year. The surface deformation map generated from the InSAR observation shows that: (1) the subsidence area is distributed along rivers; (2) the natural evolution would be the intrinsic factor for the land subsidence of the PRD; (3) the land subsidence in the PRD is significantly related to human activities (such as land reclamation, pumping groundwater for aquaculture). Due to the natural and human factors, the settlement in the PRD region will continue. These findings have guiding contributions to disaster prevention and social construction in the PRD.

\section{Abbreviation}

PRD: Pearl River Delta.

Acknowledgements

We acknowledge the contributors for the GMT. We thank JAXA for providing ALOS1/PALSAR data under Project PER2A2N038.

\section{Authors' contributions}

GL, GF, ZX, QL and SL conceptualized the manuscript and provided revision throughout the study. GL, GF and QL drafted the manuscript. ZX, QL, GF and YD processed InSAR data. GL, RX, XZ contributed to field work observation, the interpretations and discussion of the results. All authors read and approved the final manuscript.

\section{Funding}

This research was supported by the National Key Research and Development Program of China under Grants 2018 YFB0505500 and 2018YFB0505502, and National Natural Science Foundation of China (41574005).

Availability of data and materials

The ALOS/PALSAR data were provided by JAXA under Project PER2A2N038.

Ethics approval and consent to participate

Not applicable.

\section{Consent for publication}

Not applicable.

\section{Competing interests}

The authors declare that they have no competing interests.

\section{Author details}

${ }^{1}$ Guangdong Institute of Surveying and Mapping of Geology, Guangzhou 510800, China. ${ }^{2}$ School of Geosciences and Info-Physics, Central South University, Changsha 410083, China. ${ }^{3}$ School of Geography and Remote Sensing, Guangzhou University, Guangzhou 510006, China.

\section{Appendix}

\section{SAR data used in this study}

\begin{tabular}{|c|c|c|c|}
\hline Track & 459 & 460 & 461 \\
\hline Frame & $440-450$ & $430-450$ & $430-450$ \\
\hline 1 & $2006 / 12 / 22$ & $2007 / 07 / 11$ & $2007 / 01 / 25$ \\
\hline 2 & 2007/02/06 & $2007 / 08 / 26$ & $2007 / 06 / 12$ \\
\hline 3 & $2007 / 06 / 24$ & 2007/10/11 & $2007 / 07 / 28$ \\
\hline 4 & 2007/08/09 & 2008/01/11 & $2007 / 12 / 13$ \\
\hline 5 & $2007 / 12 / 25$ & $2008 / 02 / 26$ & $2008 / 01 / 28$ \\
\hline 6 & 2008/02/09 & $2008 / 05 / 28$ & $2008 / 04 / 29$ \\
\hline 7 & $2008 / 05 / 11$ & 2008/07/13 & $2008 / 06 / 14$ \\
\hline 8 & $2008,06,26$ & 2008/10/13 & $2008 / 09 / 14$ \\
\hline 9 & $2008 / 09 / 26$ & $2008 / 11 / 28$ & $2008 / 10 / 30$ \\
\hline 10 & 2008/11/11 & 2009/01/13 & $2008 / 12 / 15$ \\
\hline 11 & $2008 / 12 / 27$ & $2009 / 02 / 28$ & $2009 / 01 / 30$ \\
\hline 12 & 2009/02/11 & 2009/07/16 & $2009 / 05 / 02$ \\
\hline 13 & 2009/06/29 & $2009 / 08 / 31$ & $2009 / 08 / 02$ \\
\hline 14 & 2009/08/14 & 2009/10/16 & 2009/09/17 \\
\hline 15 & 2009/09/29 & 2009/12/01 & $2009 / 12 / 18$ \\
\hline 16 & 2009/11/14 & 2010/01/16 & $2010 / 02 / 02$ \\
\hline 17 & 2009/12/30 & 2010/03/03 & $2010 / 06 / 20$ \\
\hline 18 & $2010 / 02 / 14$ & 2010/07/19 & 2010/09/20 \\
\hline 19 & $2010 / 05 / 17$ & 2010/10/19 & $2010 / 11 / 05$ \\
\hline 20 & 2010/07/02 & $2010 / 12 / 04$ & $2011 / 02 / 05$ \\
\hline 21 & 2010/10/02 & & \\
\hline 22 & 2010/11/17 & & \\
\hline 23 & 2011/01/02 & & \\
\hline
\end{tabular}

\section{Result verification by different methods (SBAS-InSAR vs. IPTA-InSAR)}

In order to verify the reliability of our result, we processed the ALOS1/PALSAR data with the IPTA-InSAR method and compared the results with our results in Fig. 12, which shows that the two results have good consistency. This comparison also confirms the rapid subsidence in the PRD monitored by the proposed method. 

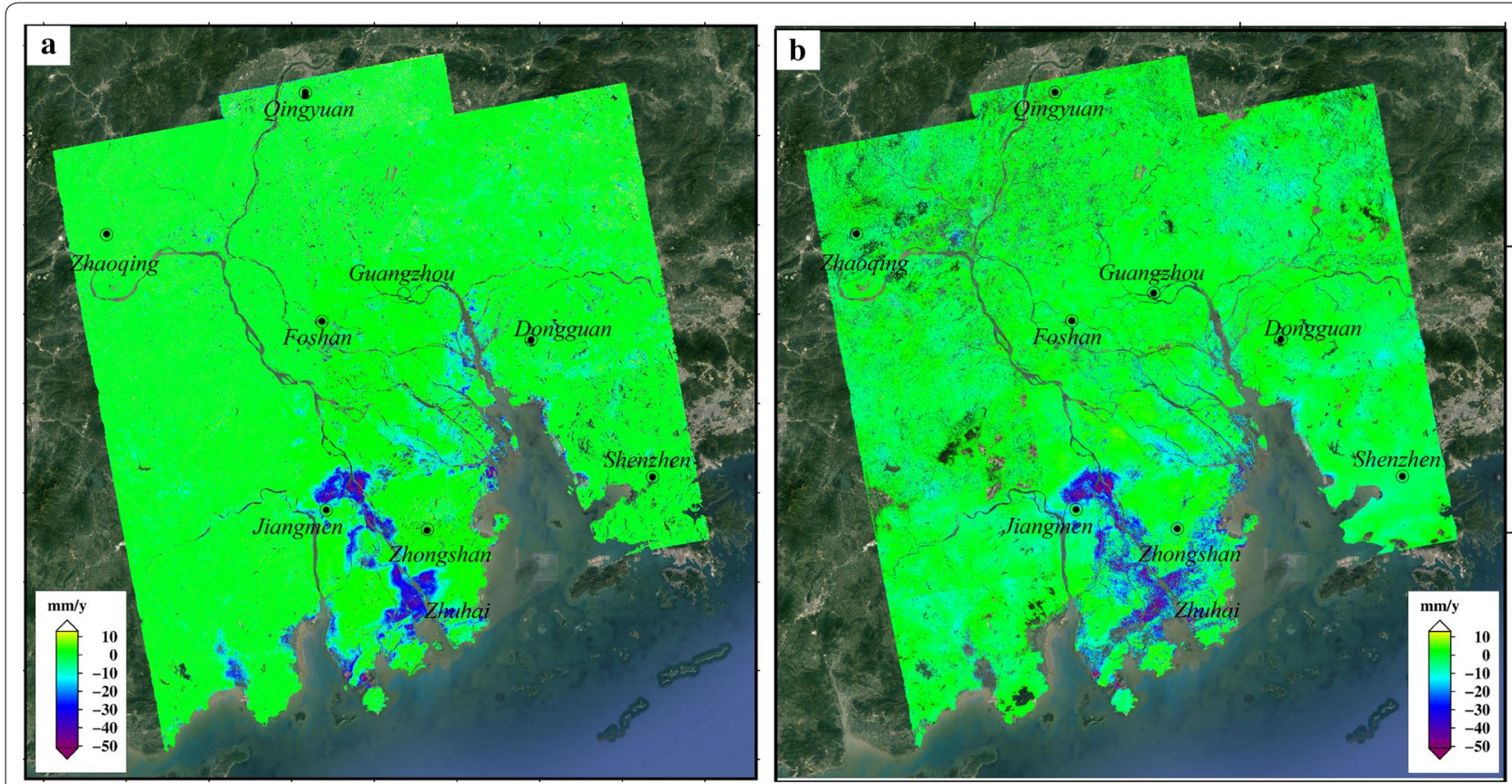

Fig. 12 Average deformation rate estimated by a IPTA-InSAR and b SBAS-InSAR method

Received: 27 May 2020 Accepted: 9 November 2020 Published online: 26 November 2020

\section{References}

Alex H-MN, Wang H, Dai Y, Carolina P, Chen W, Ge L, Du Z, Zhang K (2018) InSAR reveals land deformation at Guangzhou and Foshan, China between 2011 and 2017 with COSMO-SkyMed data. Remote Sens 10:813. https://doi.org/10.3390/rs10060813

Berardino P, Fornaro G, Lanari R, Sansosti E (2002) A new algorithm for surface deformation monitoring based on small baseline differential SAR interferograms. IEEE Trans Geosci Remote Sens 40:2375-2383. https:// doi.org/10.1109/TGRS.2002.803792

Chen F, Lin H, Zhang Y, Lu Z (2012) Ground subsidence geo-hazards induced by rapid urbanization: implications from InSAR observation and geological analysis. Nat Hazards Earth Syst Sci 12:935-942 https://doi. org/10.5194/nhess-12-935-2012

Costantini M (1998) A novel phase unwrapping method based on network programming. IEEE Trans Geosci Remote Sens 36:813-821. https://doi. org/10.1109/36.673674

Douglas I, Lawson N (2003) Airport construction: materials use and geomorphic change. J Air Transp Manag 9:177-185. https://doi.org/10.1016/ S0969-6997(02)00082-0

Erban LE, Gorelick SM, Zebker HA (2014) Groundwater extraction, land subsidence, and sea-level rise in the Mekong Delta. Vietnam Environ Res Lett 9:084010. https://doi.org/10.1088/1748-9326/9/8/084010

Ericson JP, Vörösmarty CJ, Dingman SL, Ward LG, Meybeck M (2006) Effective sea-level rise and deltas: causes of change and human dimension implications. Glob Planet Change 50:63-82. https://doi.org/10.1016/j.glopl acha.2005.07.004

Fyfe JA, Selby IC, Plater AJ, Wright MR (1999) Erosion and sedimentation associated with the last sea level rise offshore Hong Kong, South China Sea. Quat Int 55:93-100. https://doi.org/10.1016/S1040-6182(98)00030-5

Gebremichael E, Sultan M, Becker R, El BastawesyCherif MO, Emil M (2018) Assessing land deformation and sea encroachment in the Nile Delta: a radar interferometric and inundation modeling approach. J Geophys Res Solid Earth 123:3208-3224. https://doi.org/10.1002/2017JB015084
Higgins S, Overeem I, Tanaka A, Syvitski JPM (2013) Land subsidence at aquaculture facilities in the Yellow River delta, China. Geophys Res Lett 40:3898-3902. https://doi.org/10.1002/grl.50758

Higgins SA, Overeem I, Steckler MS, Syvitski JPM, Seeber L, Akhter SH (2014) InSAR measurements of compaction and subsidence in the GangesBrahmaputra Delta, Bangladesh. J Geophys Res Earth Surf 119:1768-1781. https://doi.org/10.1002/2014JF003117

Hoeksema RJ (2007) Three stages in the history of land reclamation in The Netherlands. Irrig Drain. https://doi.org/10.1002/ird.340

Hu J, Li S, Geng B (2011) Modeling the mass flux budgets of water and suspended sediments for the river network and estuary in the Pearl River Delta, China. J Mar Syst 88:252-266. https://doi.org/10.1016/j.jmars ys.2011.05.002

Hu X, Lu Z, Wang T (2018) Characterization of hydrogeological properties in Salt Lake Valley, Utah, using InSAR. J Geophys Res Earth Surf 123:12571271. https://doi.org/10.1029/2017JF004497

Huang Z, Zhang W (2004) Impacts of artificial factors on the evolution of geomorphology during recent thirty years in the Zhujiang Delta. Quat Sci 24:394-401

Jarvis A, Reuter HI, Nelson A, Guevara E (2008) Hole-filled SRTM for the globe version 4, available from the CGIAR-CSI SRTM 90m Database. http://srtm. csi.cgiar.org

Li X, Damen MCJ (2010) Coastline change detection with satellite remote sensing for environmental management of the Pearl River Estuary. China J Mar Syst. https://doi.org/10.1016/j.jmarsys.2010.02.005

Li P, Qiao P, Zheng H, Fang G, Huang G (1991) Environmental evolution in the Pearl River Delta over the past 10,000 years. China Ocean Press, Beijing (In Chinese)

Li ZW, Ding XL, Huang C, Zhu JJ, Chen YL (2008) Improved filtering parameter determination for the Goldstein radar interferogram filter. ISPRS J Photogramm Remote Sens 63:621-634. https://doi.org/10.1016/j.isprs jprs.2008.03.001

Ma P, Wang W, Zhang B, Wang J, Shi G, Huang G, Chen F, Jiang L, Lin H (2019) Remotely sensing large-and small-scale ground subsidence: a case study of the Guangdong-Hong Kong-Macao Greater Bay Area of China. Remote Sens Environ. https://doi.org/10.1016/j.rse.2019.111282

Marriner N, Flaux C, Morhange C, Kaniewski D (2012) Nile Delta's sinking past: quantifiable links with Holocene compaction and climate-driven 
changes in sediment supply? Geology 40:1083-1086. https://doi. org/10.1130/G33209.1

Maselli V, Trincardi F (2013) Man made deltas. Sci Rep 3:1926. https://doi. org/10.1038/srep01926

Mazzotti S, Lambert A, Van der Kooij M, Mainville A (2009) Impact of anthropogenic subsidence on relative sea-level rise in the Fraser River delta. Geology 37:771-774. https://doi.org/10.1130/G25640A.1

McManus I (2002) Deltaic responses to changes in river regimes. Mar Chem 79:155-170. https://doi.org/10.1016/S0304-4203(02)00061-0

Seto KC, Kaufmann RK (2006) Modeling the drivers of urban land use change in the Pearl River Delta, China: integrating remote sensing with socioeconomic data. Land Econ 79:106-121. https://doi.org/10.2307/3147108

Stramondo S, Bozzano F, Marra F, Wegmuller U, Cinti FR, Moro M, Saroli M (2008) Subsidence induced by urbanisation in the city of Rome detected by advanced InSAR technique and geotechnical investigations. Remote Sens Environ 112:3160-3172. https://doi.org/10.1016/j.rse.2008.03.008

Suzuki T (2003) Economic and geographic backgrounds of land reclamation in Japanese ports. Mar Pollut Bull 47:226-229. https://doi.org/10.1016/ S0025-326X(02)00405-8

Syvitski JPM, Saito Y (2007) Morphodynamics of deltas under the influence of humans. Glob Planet Change 57:261-282. https://doi.org/10.1016/j.glopl acha.2006.12.001

Syvitski JPM, Kettner AJ, Overeem I, Hutton EWH, Hannon MT, BrakenridgeDay GRJ, Vörösmarty C, Saito Y, Giosan L, Nicholls RJ (2009) Sinking deltas due to human activities. Nat Geosci 2:681-686. https://doi.org/10.1038/ngeo6 29

Törnqvist TE, Wallace DJ, Storms JEA, Wallinga J, Van Dam RL, Blaauw M, Derksen MS, Klerks CJW, Meijneken C, Snijders EMA (2008) Mississippi Delta subsidence primarily caused by compaction of Holocene strata. Nat Geosci 1:173-176. https://doi.org/10.1038/ngeo129

Wali M (1975) Practices and problems of land reclamation in western North America. The University of North Dakota Press, Grand Forks

Wang H, Wright TJ, Yu Y, Lin H, Jiang L, Li C, Qiu G (2012) InSAR reveals coastal subsidence in the Pearl River Delta, China. Geophys J Int 191:1119-1128 https://doi.org/10.1111/j.1365-246X.2012.05687.x
Wang XZ, Zhang HG, Fu B, Shi A (2013) Analysis on the coastline change and erosion-accretion evolution of the Pearl River Estuary, China, based on remote-sensing images and nautical charts. J Appl Remote Sens 7:073519. https://doi.org/10.1117/1.jrs.7.073519

Wang H, Feng G, Xu B, Yu Y, Li Z, Du Y, Zhu J (2017) Deriving spatio-temporal development of ground subsidence due to subway construction and operation in Delta regions with PS-InSAR data: a case study in Guangzhou, China. Remote Sens 9:1004. https://doi.org/10.3390/rs9101004

Werner C, Wegmuller U, Strozzi T, Wiesman A (2003) Interferometric point target analysis for deformation mapping. IGARSS. https://doi.org/10.1109/ IGARSS.2003.1295516

Wu ZY, Saito Y, Zhao DN, Zhou JQ, Cao ZY, Li SJ, Shang JH, Liang YY (2016) Impact of human activities on subaqueous topographic change in Lingding Bay of the Pearl River estuary, China, during 1955-2013. Sci Rep 6:37742. https://doi.org/10.1038/srep37742

Xu B, Feng G, Li Z, Wang Q, Wang C, Xie R (2016) Coastal subsidence monitoring associated with land reclamation using the point target based SBASInSAR method: a case study of Shenzhen, China. Remote Sens 8:652. https://doi.org/10.3390/rs8080652

Ye L, Preiffer KD (1990) Studies of 2D \& 3D numerical simulation of Kelvin tide wave in Nei Lingdingyang at Pearl River Estuary. Ocean Eng 8(4):33-44

Zhang X, Church JA (2012) Sea level trends, interannual and decadal variability in the Pacific Ocean. Geophys Res Lett 39:L21701. https://doi. org/10.1029/2012GL053240

Zong Y, Yim WWS, Yu F, Huang G (2009) Late quaternary environmental changes in the Pearl River mouth region, China. Quat Int 206:35-45. https ://doi.org/10.1016/j.quaint.2008.10.012

\section{Publisher's Note}

Springer Nature remains neutral with regard to jurisdictional claims in published maps and institutional affiliations.

\section{Submit your manuscript to a SpringerOpen ${ }^{\circ}$ journal and benefit from:}

- Convenient online submission

- Rigorous peer review

- Open access: articles freely available online

- High visibility within the field

- Retaining the copyright to your article

Submit your next manuscript at $\boldsymbol{\nabla}$ springeropen.com 